\title{
HUMAN RESOURCES MANAGEMENT IN THE ORGANIZATION OF THE FUTURE
}

\author{
Laurențiu Gabriel FRÂACU ${ }^{a^{*}}$, Amza MAIR $^{b}$, Anna KANT ${ }^{c}$, Raluca VASILESCU $^{d}$ \\ ${ }^{a}$ Bucharest University of Economic Studies, Romania \\ ${ }^{b, c, d}$ Valahia University of Târgoviște, Romania
}

\begin{abstract}
When it comes to today's requirements, performance, success and competitiveness are among the most important things to consider in order not only to solve the major difficulties it faces now, but also to assure development and advancement in the years ahead.

The substance and quality of Human Resources Management, which has already achieved the rank of a main subject of theoretical and applied concerns in industrialized nations, is also becoming increasingly significant. It is possible to argue that an organization's competitive edge is derived from its employees.

The new information society, as well as the knowledge-based society, has seen financial capital supplanted by human capital, which has been replaced from a strategic standpoint. This topic of scientific research on human resources in the organization of the future aroused my interest due to the fact that civil society, as well as the labor market, is in a dynamic process of consolidating the quality of human resources and this implies a change in the level of the organizational environment of an institution, the methods of working with employees and capitalizing on their potential.

This topic is topical, being treated especially by the so-called learning organizations, they are flexible and open to innovation. The aim of this paper is to study human resources, as well as to address the concept of flexible work, types and implications of work flexibility in the organization of tomorrow.
\end{abstract}

KEYWORDS: human resources, management, organisations, strategy

DOI: $10.24818 / \mathrm{IMC} / 2021 / 02.12$

\section{INTRODUCTION}

Every organization has in the structure of corporate culture a system of values and principles that are guided in its activity, a motto, mission and vision well defined (Nicolescu, O., 2008)

The organization of the future, unlike the classic, traditional one, emphasizes the idea of vision, innovation, flexibility of work, mobility and continuous modeling of human resources (Burlacu et al., 2019). Also, in such a company, which is available to learn, there is an inspirational leader, able to continuously develop through employees, to guide and increase their self-esteem, extrinsic motivation and so on. especially the intrinsic one (Androniceanu \& Burlacu, 2017), all this without imposing or instilling superiority on its subordinates, as is often the case in "closed" organizations (Ionita et al., 2009). A boss gives orders to be executed, but a leader seeks to inspire those he works with, supporting them in their work, being a true mentor.

Any innovation-oriented corporation, both organizationally and individually, will have the capacity headed for high quality products and services, thus minimizing costs (Aust, I., 2018).

The leaders of an innovative organization must be a good example of professionalism, involvement in the creation and development of human capital (Porumb, 2002).

\footnotetext{
* Corresponding author. E-mail address: gabriel.francu82@gmail.com
} 
It is the most representative for the expansion of any organization of the future, in addition to technical capital and financial, because it includes an educational capital, respectively skills acquired by individuals in the process of formal education, but also non-formal and informal (Bodislav et al., 2020).

Also, biological capital, which consists in the state of health, physical abilities of an individual, is a component of major importance in the human capital of the organization of the future (Carra et al., 2016, 2018). Biological capital is highlighted especially by occupational medicine, which plays a decisive role in the recruitment and selection process of employees (Faggianelli et al., 2018). Leaders are responsible for strengthening a competitive, dynamic organizational environment based on employee performance, which implicitly determines the performance of the organization as a whole (Radulescu et al., 2021).

The learning organization is in a continuous process of change, approaches mistakes as lessons, experiences, and tends to self-improve. The competitive advantage of a visionary organization is its ability to learn ahead of market competitors (Barrena-Martínez, 2017).

The objectives proposed to be met in this scientific research work are the following: defining and analyzing the term organization of the future, studying organizational culture and staff characteristics, presenting ways to integrate human resources in tomorrow's organization, addressing work flexibility and the concepts of telework, part-time, jobshare, flexitime, project work and intermittent work, conducting a case study on these alternatives to traditional work and, last but not least, formulating credible conclusions and suggestions.

The methodology used in carrying out this paper consists of going through several printed, electronic bibliographic sources, specialized publications, preparation of a case study, SWOT analysis and synthesis of all information resources available in the structure of the topic.

\section{LITERATURE REVIEW}

\subsection{Revolutionizing the organizational culture and ways to integrate employees in the organizational environment of the future}

The future organization is an ideal stage towards which any organization tends and which has learning as a central element (Ren, 2019). The main features of such an entity are the decentralization of control and the freedom to act in a flexible system. In addition, the manager's role is critical in fostering an atmosphere that is suitable to lifelong learning, communication, and information sharing, regardless of the impediments that may arise (Profiroiu et al., 2020).

Over the years, in the structure of an organization there have been several transitions in the organizational culture such as from standardized integration to a system of flexible integration, from a closed system to one open to the external environment, the mechanized model of work evolved towards autonomy (Baumgartner, R. J., 2017). Delegating responsibilities to managers at lower levels of management is based on characteristics of effective organization in relation to employee motivation and their attachment to the company.

Today, both managers and consultants believe that people are the most valuable resource of an organization (Negescu Oancea, et al., 2020). Organizational success depends, to a large extent, on the quality of human resources, the promotion of talents and the creation of productive teams (Nastase et al., 2020). These strategies refer to the relations with the employees, the set of intentions, attitudes, orientations and to the major directions regarding the managerial practices of recruitment, selection, maintenance and development of human resources Bodislav et al., 2020).

These dimensions of organizational culture show the contrasts between the organizational environment characterized by innovation and the traditionalist one. Adopting a leadership style based on principles such as kindness, honesty, effectiveness and professionalism in learning organizations adds value to employees, who are not only social, psychological, economic, but also 
spiritual beings who seek the meaning of their work, for it to validate human capital (Cismaru, 2012).

In an innovation-oriented organization, the management of human resources, as well as human capital, involves a series of processes that follow each other and are summarized in the recruitment and selection of staff.

These two components of human resource dynamics are closely related to current labor market trends, micro and macro-economic indicators, job characteristics and the potential candidate.

In general, the constituents of managerial thinking are expressed and are visible through correlations and perspectives. Correlations involve connections, connections between organizations, including the organizational environment, components, members, and so on (Rezaee, 2017).

Managers are productive and efficient only when they acquire and demonstrate the complex ability to think about all the correlations included in the organization, to receive, capture, design and analyze, evaluate all the factors involved (Diaz-Carrion, 2018).

Correlations are generated and expressed, manifested in people's lives and managerial practice. These refer to similarities and / or differences between aspects, hypostases, dimensions regarding the structure and processes of organizations. The performance of managers is determined by the ability to accurately distinguish contrasts and meanings for issues related to the dynamics of the organization.

Perspectives, in turn, express how to see things as a whole, to report on the problems and processes of the organization (Drucker, 2000). They might be either unilateral or bilateral in nature. In actuality, the unilateral perspective is extremely dangerous, even if it is directed toward a single purpose.

\subsubsection{Mechanisms for evaluating and motivating human resources}

Staff evaluation is seen from the whole process by which value judgments are issued to the organization's employees, to reveal the essential elements of achieving objectives and work tasks, the exercise of responsibilities and the perspective of stability of modalities and choices and promotion perspective (Brewster, 2018). The evaluation has multiple valences on the functionality and profitability of the company. It also provides important information support, both for decisions of reward, promotion, improvement, etc. on the company's staff, as well as for strategic and tactical decisions for the organizational vision.

The implications of employee evaluation should not be limited to the organization (Macke, 2019). Of paramount importance are the consequences of the evaluation process on the professional life of the members of the organization, on their job satisfaction, prospects and their evolution and, in general, on their achievement on all levels.

A reflection of the growing role that evaluation has in modern organizations is represented by the many methods and techniques used for this purpose. The assessment methods and procedures may be divided into two groups, depending on their application: general and particular.

The general evaluation methods are applicable at the level of the entire organization, regardless of the position held. Among the most common techniques in this category are notation, global assessment, and functional assessment. Contemporary valuation methods, in addition to these broad methodologies, are utilized in the modern firm, but only for specific employees, such as highly qualified managers, rather than for all employees. Their use requires more training and resources, which is why they are selective for certain job holders. The most used methods of this kind are the case, the self-assessment tests and the assessment center.

Carrying out a rigorous evaluation involves, in addition to knowing and using appropriate methods, the observance of methodological and organizational premises, which derive from the nature of the evaluation, as well as from the characteristics of the organization (Wright, 2005).

It is dependent on the type of the jobs held by those individuals, their potential, and the aims of the company that the criteria for staff assessment are determined. 
The evaluation must be uniform, in the sense that the same criteria apply to similar posts. This is done strategically, and the evaluated person faces problems specific to the position he holds (Dragomirescu, 2001).

Compliance with these requirements is a support in avoiding typical evaluation errors. It designates all the processes by which managerial positions are assigned to managerial positions located at a higher hierarchical level, as well as higher ranks or classes within the same position.

In the promotion of employees there are, as a rule, tasks and competencies, qualitatively superior responsibilities, which is reflected in the increased role they play in the organization and better remuneration.

Most people in a company have a natural desire to contribute to its success, assuming discreet but well-defined responsibilities. Unfortunately, companies have a tendency to sabotage such positive developments because they frequently fail to define clearly defined areas of responsibility and give enough resources. This situation is caused by the management style in the organization, which is also called micromanagement. People cannot properly capitalize on their potential at work when a manager is behind them, specifically when they are not trusted. Thus, micromanagement attacks self-esteem and undermines high performance.

In most organizations, impersonal relationships are more of a rule than an exception. In general, it is implicitly assumed that a human relationship diminishes the exercise of authority and will make leadership much more difficult, all this despite the fact that people are distracted by traditional management techniques and orthodoxy (Nair, 2015).

Today, hundreds of millions of women around the world are being driven into the workforce, and companies need to adapt to the overwhelming flow of part-time employees (Voegtlin, 2016). Demographic change in both developed and developing societies puts pressure on the private sector to implement creative solutions to educate, integrate and sustain a diverse and ever-changing working population (see figure 1).

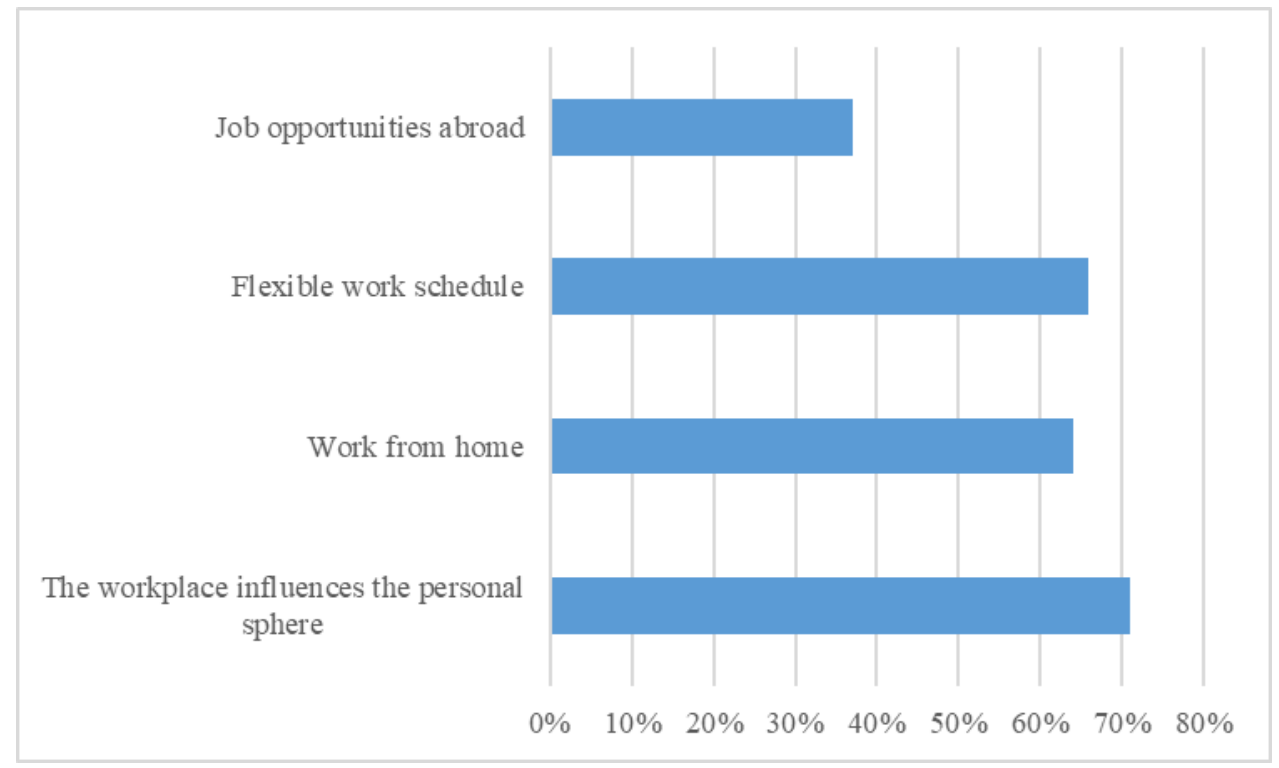

Figure 1- Current trends of young people at work

Source: http://www.forbes.ro/

\subsubsection{Work flexibility}

Most organizations want to penetrate a balance between productivity needs, the shortest possible delivery time, customer satisfaction, increased market share, innovation and needs, and so on.

Organizations' flexibility policies can take many different shapes and forms, depending on the possibilities accessible to them. Internal flexibility leads to the improvement of a company's performance in terms of innovation, productivity, and adaptability. While doing so, it provides 
advantages to employees in terms of time management, health state, and availability to carry out their responsibilities.

Economically, such types of alternative employment entail a cost-benefit interaction that is beneficial to management, employees, firm dynamics, and, indirectly, the labor market as a result of their existence.

\section{CASE STUDY: ANALYSIS OF FLEXIBLE FORMS OF WORK}

Remote work - Dexia Group, a financial institution originally from Belgium, has created a teleworking policy that provides greater flexibility for employees at work, at home, in the office or on the go. This policy includes all members of the organization and is a smart way to make efficient use of office space and save unnecessary energy costs. Although investment in telecommunications equipment is needed for work on the go and at home, net savings reach about $16 \%$.

Table 1. SWOT analysis of the teleworking concept

\begin{tabular}{|l|l|}
\hline \multicolumn{1}{|c|}{ Strenghts } & \multicolumn{1}{c|}{ Weakness } \\
\hline$\bullet$ flexibility in the organization & $\bullet$ absence of applicability \\
$\bullet$ increased confidence in job satisfaction & $\bullet$ restricted employee control \\
$\bullet$ boost productivity & $\bullet$ member communication obstacles \\
\hline Opportunities & $\bullet$ Threats \\
\hline$\bullet$ new organizational culture & $\bullet$ absence of normat \\
\hline
\end{tabular}

\section{GKN AutoStructures - creating a flexible mentality}

To prevent fluctuations in demand and encourage employees, the car and aircraft manufacturer GKN has introduced new methods of work organization, which make the production process more flexible. These innovative methods combine trust with delegating responsibilities, skills development measures, all of which have an overwhelming role in productivity and a flexible mentality, from top to bottom.

With the exception of the part-time or job-share work schedule, the total number of hours worked and the expected productivity remain the same. The flexibility of the program has a constructive impact when it considers the requirements of the staff, the economic and the working interests of the company, in a fair way. Otherwise, it can have detrimental consequences on the employee and the organization.

\section{$P R W$ - improving the work-life balance}

Flexibility is intrinsic to the culture of this Spanish parcel delivery company. One of the goals of the organization is to be family-oriented, because of which a number of formal and informal measures have been introduced to allow employees the benefit of work and privacy.

Remote work, limited working hours, time management and sabbatical leave are part of the human resources flexibility policy that stimulates organizational efficiency, in relation to staff satisfaction. There is a clear distinction between part-time work and temporary employment, which refers to the fact that in a temporary commitment the employee does not benefit from paid leave and has shortterm relationships with the organization. 
Table 2. SWOT analysis of the concept of part-time work

\begin{tabular}{|c|c|}
\hline Strenghts & Weakness \\
\hline $\begin{array}{l}>\text { time management is in favor the balance between } \\
>\text { career and private life; } \\
>\text { the right to rest, medical leave, parental } \\
>\text { suitable for pensioners, people with disabilities, } \\
\text { and other social categories that do not can work } \\
\text { full time; }\end{array}$ & $\begin{array}{l}>\text { income proportional to the work schedule; } \\
>\text { paid leave in relation to the full program } \\
>\text { work done; } \\
>\text { problems of social cohesion and assimilation } \\
\text { of organizational culture; } \\
>\text { the rules of organization and operation } \\
\text { do not is in line with the new structure. }\end{array}$ \\
\hline Opportunities & Threats \\
\hline $\begin{array}{l}\text { involvement of employees in various group } \\
\text { projects to which they adhere; } \\
\text { communication of e-mails between full-time } \\
\text { and employees those part-time, to increase work } \\
\text { efficiency. }\end{array}$ & $\begin{array}{l}\text { young employees being more flexible, the } \\
\text { company is not respond promptly to market } \\
\text { demand; } \\
\text { in favor of quantitative ones }\end{array}$ \\
\hline
\end{tabular}

Source: authors

The newest and most modern form of work flexibility is project work, in some European countries it has replaced, in the private sector, continuous and coordinated collaboration contracts. The collaborator performs out his or her actions in his or her own style, with the project-company serving as a facilitator.

\section{CONCLUSIONS}

This paper developed the idea of revolutionizing the organizational culture and staff, the characteristics of the organization of the future, as well as the attributes of human resources in such an organization. It was also highlighted the importance of the learning cycle, especially in open organizations, the differences between traditionalist and innovative, learning-oriented corporations. An essential role in the evolution of people in a company and, implicitly, of the company as a whole, is played by leadership, which must inspire confidence, enthusiasm, the desire for lifelong learning, competitiveness and commitment among the members of an organization, both individually and as well as at the collective level.

All these values are generally valid in an organization of the future and in order to remain stable it is necessary to train managers, in order to become leaders oriented towards the quality of human resources, performance, fair competition and meritocracy.

The human component of the organization of the future is a dynamic one, always being one step ahead towards innovation, flexibility, and expansion. It revolves around the network of stakeholders and shareholders, meant to propel the organization among the market leaders and beyond. At the same time, investments in human capital and talent management are one of the basic pillars of learning organizations. The more investment is made in this regard, the more the elements related to the culture of any innovative organization bear fruit. 
On the other hand, various ways of integrating employees in the organizational environment of the future have been developed, namely the processes of planning, recruitment and selection of human resources, mechanisms for motivating and evaluating staff.

However, the roles attributed to motivation in the internal framework, of the organization and in the external, socio-economic framework were illustrated, these being divided into managerial, individual, organizational, economic and social role.

All these refer to the extrinsic motivation, but also to the intrinsic one, having a significant impact on the individuals in the organization, the organization itself and, last but not least, on the society to which they belong, at micro and macroeconomic level.

In the case of various types of activity, the individually and collectively labor contracts are distinct and address problems such as the wage scale, the bonuses that are included in the salary, bonuses, the right to rest leave, medical leave, maternity and paternity leave, and other benefits.In order to strengthen such businesses, it is necessary to facilitate the absorption of funds for investment in SMEs and to combat fiscal and bureaucratic barriers.

This scientific approach treated in this paper is a starting point in the development of more specialized studies, which will generate new perspectives on human resources of future organizations.

\section{AKNOWLODGMENT}

Thanks to the team for their help in writing this article. I would like to express my gratitude to my colleagues for their continued encouragement, critical analysis of this article, and guidance.

\section{REFERENCES}

Androniceanu, A., \& Burlacu, S. (2017). Intelligent System for Assessment and Grading Based on Docimologic Tests. eLearning \& Software for Education, 2, 33-40

Carra, C., Burlacu, S., \& Faggianelli, D. (2016). Violence Within Organizations In The Health And Medico-Social Sectors, Comparative Analysis France-Romania. Administratie si Management Public, (27), 123.

Aust, I., Muller-Camen, M., Poutsma, E. (2018). Sustainable HRM: A comparative and international perspective, InC. Brewster, E. Farndale, \& W. Mayrhofer (Eds.), Handbook of research in comparative human resource management (2nded., pp. 358-369).

Baumgartner, R. J., Rauter, R. (2017). Strategic perspectives of corporate sustainability management to develop a sustain-able organization. Journal of Cleaner Production, 140, 81-92.

Bodislav, D. A., Buzoianu, O. A. C., Burlacu, S., \& Rădulescu, C. V. (2020). Analysis of companies in Romania from the perspective of risk perception and the management needs thereof. Economic Convergence in European Union, 341.

Brewster, C., Mayrhofer, W., Farndale, E. (2018), Handbook of research on comparative human resource management. Chel-tenham, England: Edward Elgar

Burlacu, S., Alpopi, C., Mitrită, M., \& Popescu, M. L. (2019). Sustainable e-Governance and Human Resource Development. European Journal of Sustainable Development, 8(5), 16.

Burlacu, S., Profiroiu, A., \& Vasilache, P. C. (2019). Impact Of Demography On The Public Finance Of The European Union. Calitatea, 20(S2), 136-138.

Carra, C., Burlacu, S., \& Faggianelli, D. (2018). Violence Within the Organizations of Health and Medico-Social Sector a Comparative Analysis of France and Romania. Economics, Management and Financial Markets, 13(3), 185-202. 
Cheltenham, England, Edward E., Barrena-Martínez, J., López-Fernández, M., Romero-Fernández, P. M., (2017). Towards a configuration of socially responsible human resource management policies and practices: Findings from an academic consensus. The International Journal of Human Resource Management, 23(1), 1-37

Cismaru, D., Iacob, D. (2012). Organizația inteligentă, Facultatea de Comunicare și Relații Publice, București, pag. 6-7

Diaz-Carrion, R., López-Fernández, M., Romero-Fernandez, P. M. (2018). Developing a sustainable HRM system from acontextual perspective. Corporate Social Responsibility and Environmental Management, 25(6), 1-11

Dragomirescu, H. (2001). Organizații bazate pe cunoaștere, Academia de Studii Economice, București, p.4

Drucker, F. (2000). Organizația viitorului, Editura Teora, București, pag. 173-174

Faggianelli, D., Burlacu, S., \& Carra, C. (2018). Victimization of Health Professionals in Bucharest Service Relations and Social Work Relationships. Administratie si Management Public, (30), 109-126.

Ioniță, F., Ursăcescu, M., \& Burlacu, S. (2009). Public Services as Poles of Regional Competitiveness in Sustainable Development. Revista de Management Comparat International/Review of International Comparative Management, 10(3), 552-565.

Macke, J., Genari, D. (2019). Systematic literature review on sustainable human resource management, Journal of Cleaner Production, 208(1), 806-815

Nair, R. S. (2015). A review of the cause-effect relationship between CSR and HR. The Internati onal Journal of Business \&Management, 3(12), 63-91

Năstase, M., Roja, A., Burlacu, S., Coroban, L., Matis, C., Cristescu, I., \& Cristache, N. (2020). Perspectives Regarding the Organizational Culture within the Romanian Textile Industry. Industria Textila, 71(1), 73-80.

Negescu, M. D., Burlacu, S., Mitriţă, M., Buzoianu, O C A. (2020) Managerial Analysis of Factoring at the International Level Challenges of the Contemporary Society. Proceedings; Cluj-Napoca Vol. 13, Iss. 1: 99-102. Cluj-Napoca: Babes Bolyai University.

Nicolescu, O., Verboncu, I. (2008). Fundamentele managementului organizației, Ed. Universitară, București

Porumb, E. (2002). Capitalul uman și social, Cluj-Napoca, EFES, pp. 39-45

Profiroiu, M. C., Rădulescu, C. V., Burlacu, S., \& Guţu, C. (2020). Changes and trends in the development of the world economy. In Competitivitatea şi inovarea în economia cunoaşterii (pp. 324-330).

Rădulescu, C. V., Ladaru, G. R., Burlacu, S., Constantin, F., Ioanăș, C., Petre, I. L. (2021) Impact of the COVID-19 Pandemic on the Romanian Labor Market. Sustainability, 13, 271. https://doi.org/10.3390/su13010271

Ren, S., \& Jackson, S. E. (2019). HRM institutional entrepreneurship for sustainable business organizations. Human Resource Management Review, 30(3), 1-18, doi: 10.1016/j.hrmr.2019.100691

Rezaee, Z. (2017). Corporate sustainability: Theoretical and integrated strategic imperative and pragmatic approach. The Journal of Business Inquiry, 16, 181-212.

Voegtlin, C., Greenwood, M. (2016). Corporate social responsibility and human resource management: A systematic review and conceptual analysis. Human Resource Management Review, 26(3), 181-197.

Wright, P. M., Snell, S. A., Dyer, L. (2005). New models of strategic HRM in a global context. The International Journal of Human Resource Management, 16(6), 875-881. 